\title{
Non-BRCA Gene Mutation
}

National Cancer Institute

\section{Source}

National Cancer Institute. Non-BRCA Gene Mutation. NCI Thesaurus. Code C161911.

A genetic finding indicating the presence of gene mutations in a sample that may be associated with cancer predisposition and are in located in genes other than BRCA1 and BRCA2. 